\title{
DEL CONSTITUCIONALISMO CLÁSICO AL CONSTITUCIONALISMO PLURAL: LA DISPUTA POR LA CAPACIDAD REGULATORIA DE LA SOCIEDAD EN PERSPECTIVA TEÓRICA
}

\author{
FROM CLASSICAL CONSTITUTIONALISM TO PLURAL \\ CONSTITUTIONALISM: THE DISPUTE BY THE REGULATORY CAPACITY \\ OF THE SOCIETY IN THEORETICAL PERSPECTIVE
}

\section{DO CONSTITUCIONALISMO CLÁSSICO AO CONSTITUCIONALISMO PLURAL: A DISPUTA PELA CAPACIDADE REGULATÓRIA DA SOCIEDADE EM UMA PERSPECTIVA TEÓRICA}

\section{Gina Chávez Vallejo*}

Resumo: La Constitución ecuatoriana vigente desde el 2008, define al Estado como constitucional de derechos y justicia, plurinacional e intercultural, entre otros atributos. $\mathrm{Al}$ reconocer el derecho indígena en pie de igualdad con la justicia ordinaria, a la vez que instaura un pluralismo jurídico pragmático al incorporar 'otro' sistema jurídico que responde a 'otra' tradición jurídica, determina que la interpretación constitucional deberá también incluir una interpretación intercultural. Todo lo cual inaugura un constitucionalismo plural, esto es, un Orden Jurídico pluralista. El Nuevo Constitucionalismo Latinoamericano, en el caso ecuatoriano específicamente, antes que una teoría sobre el Derecho o la Constitución es la concreción político-normativa, de un largo proceso de reflexión y lucha por la democratización del Estado, la que incluyó una disputa por la capacidad regulatoria de la sociedad. No obstante, se trata de un constitucionalismo pragmático, sus bases teóricas se las puede identificar y evaluar en una revisión de los postulados que encierran los mandatos constitucionales. Es precisamente lo que propone el presente trabajo.

Palabras clave: Constitucionalismo; Derecho indígena; Pluralismo Jurídico.

\begin{abstract}
The Ecuadorian Constitution in force since 2008, defines the State as constitutional rights and justice, plurinational and intercultural, among other attributes. By recognizing indigenous law on an equal footing with ordinary justice, while establishing a pragmatic legal pluralism by incorporating 'another' legal system that responds to 'another' legal tradition, determines that the constitutional interpretation should also include an intercultural interpretation. All of which inaugurates a plural constitutionalism, that is, a pluralist juridical order. The New Latin American Constitutionalism, in the Ecuadorian case specifically, before a theory about the Law or the Constitution is the political-normative concretion, of a long process of reflection and struggle for the democratization of the State, which included a dispute over the capacity regulation of society. However, it is a pragmatic constitutionalism, its theoretical bases
\end{abstract}

\footnotetext{
* Doctora en Derecho, Ciencia Política y Criminología. Máster en Derecho Constitucional. Doctora en Jurisprudencia. Profesora Titular Principal del Instituto de Altos Estudios Nacionales (IAEN) desde el 2010. Correo electrónico: gina.chavez@iaen.edu.ec.
} 
Del constitucionalismo clásico al constitucionalismo plural: la disputa por la capacidad regulatoria de la sociedad en perspectiva teórica

can be identified and evaluated in a review of the postulates that contain the constitutional mandates. It is precisely what the present work proposes.

Keywords: Constitutionalism; Indigenous law; Legal Pluralism.

Resumo: A Constituição do Equador em vigor desde 2008, define o Estado como direitos constitucionais e justiça, plurinacional e intercultural, entre outros atributos. Ao reconhecer o direito indígena em pé de igualdade com a justiça comum, ao estabelecer um pluralismo jurídico pragmático, incorporando "outro" sistema jurídico que responde a "outra" tradição legal, determina que a interpretação constitucional também deve incluir uma interpretação intercultural . Tudo o que inaugura um constitucionalismo plural, isto é, uma ordem jurídica pluralista. O novo constitucionalismo latino-americano, no caso equatoriano especificamente, antes de uma teoria sobre a Lei ou a Constituição é a concretização político-normativa, de um longo processo de reflexão e luta pela democratização do Estado, que incluiu uma disputa sobre a capacidade regulação da sociedade. No entanto, como é um constitucionalismo pragmático, suas bases teóricas podem ser identificadas e avaliadas em uma revisão dos postulados que contêm os mandatos constitucionais. É precisamente o que o presente trabalho propõe.

Palavras-chave: Constitucionalismo; Direito indígena; Pluralismo Jurídico.

\section{INTRODUCCIÓN}

La Constitución ecuatoriana vigente desde el 2008, que varios autores la ubican dentro de la corriente denominada Nuevo Constitucionalismo Democrático Latinoamericano, define al Estado como constitucional de derechos y justicia, plurinacional e intercultural, entre otros atributos. Con ello, no solo se cambia el sistema de fuentes del Derecho ${ }^{1}$ al poner a la Constitución como fuente primaria, sino también le da coherencia con su fundamentación democrática, reconociendo al derecho internacional de los derechos humanos y a la interpretación constitucional como fuentes del Derecho.

$\mathrm{Al}$ reconocer el derecho indígena en pie de igualdad con la justicia ordinaria, a la vez que instaura un pluralismo jurídico pragmático al incorporar 'otro' sistema jurídico que responde a 'otra' tradición jurídica, determina que la interpretación constitucional deberá también incluir una interpretación intercultural. Todo lo cual inaugura un constitucionalismo plural, esto es, un Orden Jurídico pluralista.

El Nuevo Constitucionalismo Latinoamericano, en el caso ecuatoriano específicamente, antes que una teoría sobre el Derecho o la Constitución es la concreción político-normativa, de un largo proceso de reflexión y lucha por la democratización del Estado, la que incluyó una disputa por la capacidad regulatoria de la sociedad. Busca saldar cuentas con el Estado colonial persistente a través de nuevas y renovadas formas 
de colonialidad. Se propone reconstruir las bases histórico-sociales de la sociedad ecuatoriana imprimiendo nuevos sentidos al $E \operatorname{stado}^{2}$, al Derecho ${ }^{3}$, a la economía ${ }^{4}$, a la política ${ }^{5}$. Antes que una teoría del Estado o del Derecho es una formulación constitucional que tiene implícita una teoría del Estado y la sociedad, donde el Derecho es instrumento de dicha relación 6 .

Por otro lado, el Nuevo Constitucionalismo Latinoamericano se preocupa de incorporar $^{7}$ en los textos constitucionales todos los avances del neoconstitucionalismo europeo y del constitucionalismo estadounidense, fundamentalmente, esto es: la rigidez constitucional, el valor normativo de la Constitución, la aplicación directa de la Constitución, el control de los poderes del Estado, un sistema reforzado de garantías constitucionales, la omnipresencia de principios y reglas, los principios como criterios de interpretación, el activismo judicial; todos los cuales son aplicables a un constitucionalismo que busca solucionar los problemas de la desigualdad social y sentar las bases para un nuevo tipo de Estado. Esto ha hecho que varios autores hablen de un constitucionalismo experimental o en transición ${ }^{8}$. Yo me distancio de las lecturas evolucionistas y de la transición y asumo una visión más bien histórica que ve el surgimiento de un constitucionalismo social y democrático que responde a un momento histórico determinado y pretende la solución de determinados y puntuales problemas históricos.

No obstante, se trata de un constitucionalismo pragmático, sus bases teóricas se las puede identificar y evaluar en una revisión de los postulados que encierran los mandatos constitucionales. Es precisamente lo que propone el presente trabajo.

\section{BASES TEÓRICAS DEL PLURALISMO JURÍDICO ECUATORIANO}

Si algo caracteriza a la actual sociedad globalizada es la importancia adquirida del concepto de pluralismo en el debate político, económico, social, cultural y jurídico, poniendo en duda las visiones monistas del mundo, esto es, aquellas que pretender reducir la diversidad de proyectos de vida y de valores morales a tipos homogéneos de sociedad (sociedades basadas en los valores del liberalismo ideológico), de ciudadanía (ciudadano-cliente) y de Estado (dependientes y funcionales a los grandes intereses geopolíticos de nivel global $)^{9}$.

Tanto la globalización social como las actuales necesidades del capitalismo mundial han llevado a los propios liberales a ampliar la perspectiva más allá del R. Fac. Dir. UFG, v. 41, n. 3, p.34-50, set/dez. 2017 
Del constitucionalismo clásico al constitucionalismo plural: la disputa por la capacidad regulatoria de la sociedad en perspectiva teórica

pluralismo social y el pluralismo político que dominaban el debate, buscando domesticar la pluralidad de visiones morales en conflicto, por lo general, siempre desde una perspectiva funcional e instrumental a los valores liberales y a los requerimientos del capitalismo global.

Frente a las principales versiones del pluralismo liberal contemporáneo se han alzado posiciones que buscan desvelar el nuevo ejercicio de reduccionismo social que significan las propuestas liberales, el multiculturalismo entre ellas, proponiendo perspectivas más amplias que representen de mejor manera la complejidad social, pero, sobre todo, las exclusiones que subsisten en la sociedad plural.

Este debate también alcanza al Derecho y se ha traducido en una amplia discusión acerca del pluralismo jurídico, esto es, de la existencia de otros órdenes jurídicos distintos al orden jurídico nacional - actuando a nivel supraestatal o infra estatal -, que conviven y disputan la capacidad normativa del Estado nacional. Se trata, por tanto, de un debate que confronta las fórmulas liberales unitaristas, monoclasistas, individualistas e instrumentalistas con las posiciones que abogan por miradas pluralistas, multiclasistas, republicanistas y de justicia social.

Este debate es animado por los desafíos de la sociedad global, lo que ha llevado al propio liberalismo a proclamarse plural - sea en la versión liberal de Hart (1997), Rawls (1995) o Habermas (1998), o en una versión radical que discute la noción de igualdad compleja: Miller, Walzer, Elser, Moller Okin (1996), entre otros.

Pero, adicionalmente, la evolución del debate plantea la idea de un pluralismo transformador que supone la superación teórica y material de al menos dos de las principales visiones hegemónicas de pluralismo: la liberal, que reduce la noción de pluralismo al pluralismo político y convirtiendo a este en eje del Estado democrático; y la multiculturalista, también de raigambre liberal, que propone una respuesta puntual a la naturaleza étno-cultural de los conflictos contemporáneos.

Por su lado, una gama de posiciones comunitaristas - republicanistas (Taylor, 1993 y Sandel, 2000), neomarxistas (Mouffe, 1999) y críticas (Wolkmer, 2006), sostienen perspectivas posliberales, ontologistas, posthumanistas, esencialistas o democráticas del pluralismo, atacando los reduccionismos liberales y volviendo a colocar perspectivas comunitaristas de nuevo cuño en donde se destrona la centralidad del individuo y del Estado y se apela por nuevos tipos de sociedades en donde salgan a la luz los intereses colectivos asumiendo su papel en la recomposición del Orden. 
El debate pone a discusión diversidad de temas como el Estado, la justicia social, las libertades, los derechos humanos, las minorías, entre otros. Las críticas apuntan a un cuestionamiento de las nociones liberales de individualismo, racionalismo, neutralidad, aculturalidad y unificación, a la mediación que estas nociones realizan entre lo universal y lo particular, y al reduccionismo social que ello supone.

Se busca, por un lado, dibujar un estatuto propio de las identidades diferenciadas, por lo menos a las de raigambre étno-cultural - aunque también a las diferenciaciones sexuales -, no solo por estar atrapadas en una serie de condicionamientos históricos y sociales, sino porque en estos ámbitos no opera la 'libre elección': se 'es' indígena, no 'se hace' indígena.

Por otro lado, plantean reconstruir el Estado democrático superando el unitarismo, el individualismo, el universalismo como entidades ontológicas y optando por una democracia radical que reconstruya la noción de sujeto, que incluya a los sujetos colectivos de juridicidad, que enfrente y maneje las conflictividades intersubjetivas y de las colectividades, que reordene el espacio público bajo modelos descentralizadores y participativos, y que coloque a la interculturalidad como mecanismo de relación entre lo estatal y lo social.

Como se puede advertir, el pluralismo, aún en su vertiente más radical, no busca sustituir al Estado sino transformar sus cimientos unificadores, universalistas, estatistas, asépticos y avalorativos, aspiraciones en las que coinciden con otras líneas críticas, dentro y fuera del Derecho.

\section{DEL CONSTITUCIONALISMO CLÁSICO AL CONSTITUCIONALISMO PLURAL}

Se puede sostener que una renovada perspectiva pluralista del constitucionalismo contemporáneo es la característica más novedosa y transformadora de lo que se identifica como Nuevo Constitucionalismo Latinoamericano ${ }^{10}$, que hace referencia a los modelos constitucionales que emergieron en América Latina a partir de la década de los años noventa en varios países del Continente.

El constitucionalismo plural que aquí se sostiene, encuentra sus bases teóricas y metodológicas en un conjunto de postulados posliberales, neomarxistas, republicanistas, neoconstitucionalistas, neoinstitucionalistas, poscoloniales, principalmente planteados desde una perspectiva democrática y social, y apuntando a una R. Fac. Dir. UFG, v. 41, n. 3, p.34-50, set/dez. $2017 \quad$ ISSN 0101-7187 
Del constitucionalismo clásico al constitucionalismo plural: la disputa por la capacidad regulatoria de la sociedad en perspectiva teórica

redefinición del rol del Estado de Derecho en la sociedad, a una recomposición de las relaciones sociales, a una reformulación del sentido del poder y de la democracia, e incorporando nuevas formas económicas y culturales. En este sentido, antes que una perspectiva teórica, el constitucionalismo plural es una formulación de naturaleza práctica que opera en un Estado en transformación, esto es, un Estado que se propone varias rupturas de dimensiones históricas, culturales y políticas.

En este sentido, las bases teóricas del constitucionalismo plural las podemos rastrear siguiendo el debate contemporáneo sobre el derecho, la constitución y el constitucionalismo democrático, no solo porque en torno a estos temas ha girado, sustancialmente, la discusión jurídica en los últimos setenta años, sino porque esta discusión ha definido muchos de sus contenidos.

Es importante resaltar que el debate teórico aludido se ha dado a la par y como respuesta frente a las significativas transformaciones sociales, políticas, económicas y culturales que han sufrido nuestras sociedades fruto de la globalización y el neoliberalismo, de las nuevas relaciones de poder que esta instaura y de la pugnas sociales y emergencias sociales que se dieron dentro y fuera de las fronteras del Estado. Todo lo cual cambió el panorama material y teórico del Estado de Derecho, de la política y de la sociedad, no precisamente en un sentido democrático, sino reforzando el poder de las grandes potencias, las corporaciones e instituciones supraestatales y transnacionales por encima de los intereses de los Estados-nación y sus habitantes.

Los ajustes en la política y el derecho no se dan necesariamente a favor de los ciudadanos dado que se ven compelidos o están comprometidos en la tarea de apuntalar los intereses del nuevo capitalismo mundial. Como respuesta, bullen demandas ciudadanas exigiendo salidas por fuera de los moldes neoliberales.

Como consecuencia, en el mundo occidental, desde la post Segunda Guerra Mundial, se vienen dando importantes desplazamientos en la teoría y en la práctica jurídica, lo que también ha transformado el panorama del Derecho.

Para efectos del presente trabajo vale mencionar que las líneas teóricas que en mayor medida contribuyeron a tales transformaciones en el campo del Derecho son: el abandono de las teorías generales por el estudio de las prácticas del derecho; el tránsito del formalismo al sustancialismo; el desplazamiento del legicentrismo a la constitucionalización del derecho; el cuestionamiento de la representación jerárquica del derecho para consolidar una dimensión democrática participativa del derecho; el cuestionamiento a la neutralidad para favorecer el compromiso con la vigencia material 
de los derechos; el cuestionamiento del enfoque monoclasista a favor de un enfoque pluralista.

En cuanto al constitucionalismo contemporáneo, sus rasgos característicos son: la constitucionalización del Orden Jurídico, que significa, entre otras cosas, la vigencia de una constitución rígida que contiene no solo la clásica división de los poderes, control y límites al poder - que también se ven redefinidos -, sino que incluye una dimensión normativa de la constitución y procedimientos efectivos de control de constitucionalidad y garantía de los derechos, lo que a su vez modifica las fuentes del derecho, tornando sustancial, no solo formal, el 'ser' y el 'deber ser' del Derecho.

Las disquisiciones jurídicas, que mucho menos se agotan en esta corta exposición, acompañaron en Latinoamérica a una emergencia de la movilización y la demanda de la participación social en las definiciones del poder y, por consiguiente, de los significados del derecho; cuestión que se asienta en los postulados de la actual doctrina de los Derechos Humanos ${ }^{11}$, marcada por el rol que juegan hoy en día los derechos y las garantías. Esto coloca a la cuestión de la legitimidad del poder, esto es, a la democracia, también en la esfera de la discusión respecto de las prácticas del derecho y del papel del Estado, lo que en el Nuevo Constitucionalismo Latinoamericano se expresa como el tránsito de la representación jerárquica del Derecho hacia una dimensión participativa del Derecho.

Esta dimensión participativa apunta a la superación de la utopía conservadora de una democracia sin pueblo o, como dijera Hart, una mera administración aséptica de las cosas cuyas premisas son incuestionadas y blindadas en el procedimiento. Los postulados neorrepublicanistas de ciudadanía acompañan estas reflexiones.

Estamos, por tanto, frente a un nuevo escenario jurídico donde el Derecho ya no es lo que era, no solo por las transformaciones internas que ha sufrido sino porque la dinámica de la sociedad contemporánea así lo exige.

El debate sobre legicentrismo y constitucionalismo en América Latina de finales del siglo $\mathrm{XX}$ se tradujo en procesos de reforma constitucional en donde el legicentrismo fue duramente cuestionado, mientras el constitucionalismo fue ganando terreno como mecanismo de renovación del Derecho, y en la versión del Nuevo Constitucionalismo Latinoamericano, como un instrumento de transformación social.

\section{ALGUNAS IMPUGNACIONES AL CONSTITUCIONALISMO CLÁSICO}


Del constitucionalismo clásico al constitucionalismo plural: la disputa por la capacidad regulatoria de la sociedad en perspectiva teórica

Volver al pluralismo jurídico no significa regresar a la pluralidad de ordenamientos propia del feudalismo y el colonialismo, es más bien superar una forma de Estado que ya no resiste como tal frente a las nuevas realidades que por efecto de la globalización y de los cambios que esta genera, así como por la pluralidad de órdenes normativos que opera en el ordenamiento interno del Estado, transforman, se imponen y conforman lo que es actualmente el Derecho.

Es en este sentido que el pensamiento crítico, interdisciplinario y pluralista - en una variedad amplia de vertientes -, realiza una crítica interna y externa del derecho y apunta a uno de los pilares del derecho liberal y social, el monismo jurídico.

Se critica al monismo jurídico tanto como teoría (el sustento teórico de la idea de que el Derecho es derecho del Estado, y que solo el derecho del Estado es Derecho y de que el Derecho no se define por su contenido, sino por la organización del uso de la fuerza, en razón del contractualismo en la producción del Derecho), como ideología (la comprensión de que por el mero hecho de ser un ordenador regular de convivencia el Derecho garantiza ciertos valores morales como la seguridad, la certeza, la previsibilidad de las conductas o la paz, de lo que deriva la obligación de obediencia al Derecho), y como metodología (asumir al Derecho como neutro, avalorativo, que puede ser definido como un hecho y no como un valor, que el único que produce Derecho es el Estado a través de sus agentes jurídicos, que la interpretación del Derecho es un ejercicio técnicojurídico, así como la concepción piramidal del Derecho en torno al principio de jerarquía, y el legicentrismo o Derecho centrado en la ley).

Respecto de la producción hegemónica del Derecho, cuando se afirma que el monopolio de la producción jurídica pertenece al Estado, esto supone a su vez dos cosas: que la creación del Derecho, en lo que a fuentes se refiere (potestad legislativa), es de exclusivo ejercicio de los órganos estatales habilitados ${ }^{12}$ para ello; y por otro, que son los órganos del Estado habilitados para tales efectos los que se encargarán de decidir qué significados y alcances tienen esas normas expedidas con anterioridad. Este es el núcleo de la potestad jurisdiccional, la potestad para decir el Derecho.

A estos postulados se oponen argumentos que sostienen que ni es el Estado el único que produce Derecho, ni tampoco es el único que adjudica sentido a las normas jurídicas. También se cuestiona que el monopolio de la producción del Derecho por parte de los agentes estatales y la reducción del Derecho a mero organizador del uso de la fuerza, solo apunta a afianzar la hegemonía del poder del Estado para justificar los intereses que realmente encubre. Por esta vía, se justifica una comprensión del Derecho 
en términos de coexistencia de ordenamientos jurídicos, cuya relación puede ser entendida en términos de descentralización, autonomía, coordinación y participación en el proceso de producción y otorgamiento de sentidos, lo que incluye también el reconocimiento material y jurídico de 'otros' derechos, esto es, otros ordenamientos jurídicos.

\title{
5. EL DERECHO INDÍGENA COMO PARADIGMA DEL CONSTITUCIONALISMO PLURAL
}

En el constitucionalismo ecuatoriano, el control constitucional de las decisiones judiciales no se agotan en la revisión de las sentencias o autos con fuerza de sentencia emitidos por los jueces de la justicia ordinaria, sino que abarca, además, a las decisiones que toman las autoridades de las comunidades, pueblos y nacionalidades indígenas en el ejercicio de funciones jurisdiccionales. El Artículo 171 de la Constitución lo expresa así:

\begin{abstract}
Las autoridades de las comunidades, pueblos y nacionalidades indígenas ejercerán funciones jurisdiccionales, con base en sus tradiciones ancestrales y su derecho propio, dentro de su ámbito territorial, garantizando la participación y decisión de las mujeres. Las autoridades aplicarán normas y procedimientos propios para la solución de sus conflictos internos, y que no sean contrarios a la Constitución y a los derechos humanos reconocidos en instrumentos internacionales.

El Estado garantiza que las decisiones de la jurisdicción indígena sean respetadas por las instituciones y autoridades públicas. Dichas decisiones estarán sujetas al control de constitucionalidad. La ley establecerá los mecanismos de coordinación y cooperación entre la jurisdicción indígena y la jurisdicción ordinaria (ECUADOR, 2008).
\end{abstract}

Previamente a esta disposición, el Artículo 57 reconoce y garantiza “[...] a las comunas, comunidades, pueblos y nacionalidades indígenas, de conformidad con la Constitución y con los pactos, convenios, declaraciones y demás instrumentos internacionales de derechos humanos, los siguientes derechos colectivos: (10) Crear, desarrollar, aplicar y practicar su derecho propio o consuetudinario, que en ningún caso podrá vulnerar los derechos de las mujeres, de las niñas, niños y adolescentes" (ECUADOR, 2008).

Complementariamente, en el Título IV, Capítulo cuarto, en lo referente a los jueces de paz, establece que "[...] Las juezas y jueces de paz resolverán en equidad y tendrán competencia exclusiva y obligatoria para conocer aquellos conflictos 
Del constitucionalismo clásico al constitucionalismo plural: la disputa por la capacidad regulatoria de la sociedad en perspectiva teórica

individuales, comunitarios, vecinales y contravenciones, que sean sometidos a su jurisdicción, de conformidad con la ley. En ningún caso podrá disponer la privación de la libertad ni prevalecerá sobre la justicia indígena” (ECUADOR, 2008).

La protección que otorga la Constitución ecuatoriana al ejercicio del derecho propio de las comunidades, pueblos y nacionalidades indígenas, como se ha podido constatar, consiste en reservar la evaluación de las actuaciones de las autoridades indígenas que resuelven conflictos internos, al máximo órgano de control constitucional, la Corte Constitucional.

Esto implica, en primer lugar, que las actuaciones jurisdiccionales de las autoridades indígenas quedan excluidas del examen de legalidad; en segundo lugar - y de conformidad con las atribuciones generales adjudicadas a la $\mathrm{CC}-$, que la evaluación de las decisiones de la autoridad indígena se circunscribe a realizar un control externo y no de corrección jurídica de las decisiones de la autoridad indígena, tal como sucede con la acción extraordinaria de protección (arts. 94 y 436 de la CPE). En este sentido, la Corte Constitucional se limitará a examinar si en la sustanciación del caso, la autoridad indígena vulneró el debido proceso 'propio'13, u otros derechos reconocidos en la Constitución para todos los ciudadanos, en general, y para los ciudadanos indígenas, en particular; todo lo cual deberá hacerse en clave intercultural y a la luz del derecho indígena. Cosa por demás extraña y compleja tanto desde el punto de vista del constitucionalismo tradicional como del contemporáneo.

Por lo anteriormente anotado, es posible sostener que el pluralismo jurídico de naturaleza étnico-jurídica, valga decir, el que incluye al derecho indígena dentro de la estructura de sistema judicial de carácter nacional, representa el paradigma del constitucionalismo plural, lo que equivale a decir que tiene la vocación de articular su contenido con la correspondiente justificación teórica, ideológica y metodológica, como una propuesta de Estado, de sociedad, de Derecho y de política.

La democracia capitalista ha logrado sortear varias crisis al largo de los dos últimos siglos. El Estado de Derecho ha sido un gran contenedor de muchas de las crisis y fue porque supo concebir un paradigma lo suficientemente coherente para los intereses concretos que busca resguardar. El Derecho resultó ser la varita mágica para reducir la multiplicidad y el caos que reinaba en aquel estado de cosas anterior, asumiendo la capacidad de justificar - santificar- decisiones en nombre del pueblo y bajo legitimación estatal. Todos los elementos emergentes del estado de cosas anterior se fueron alineando de manera exitosa: Estado territorial - derecho estatalizado - economía 
capitalista - democracia representativa - persona como sujeto - sujeto como ciudadano. Los campos delimitados entre lo público y lo privado lograron importantes avances para la fórmula civilizatoria de la modernidad.

Pero, ¿qué de esa realidad que se describe caracteriza la contemporaneidad? Probablemente ninguna, salvo algunos imaginarios que aún le dan crédito al Estado nacional como fórmula para democratizar la sociedad y resguardarse ante la voracidad del capital internacional y la preponderancia del gobierno corporativo transnacional.

Tal vez esto está detrás de las últimas transformaciones constitucionales que ocurrieron en América Latina en los dos últimos decenios y que hablan de un Nuevo Constitucionalismo Latinoamericano, que alberga un constitucionalismo plural, como fórmula de renovación democrática de la sociedad y del Estado. La fórmula es de naturaleza intuitiva, por lo que, más que las certezas, guían las aspiraciones, las necesidades, las carencias los temores y las dignidades. Por eso también está en constante revisión, reformulación, resistencia y confrontación.

Es en este contexto de las inconformidades colectivas, de intuiciones acerca de lo nuevo, de sobreinterpretaciones ${ }^{14}$ y de certezas esquivas, es que debe entenderse el revisionismo latinoamericano del Derecho y, dentro de él, la crítica que plantea el pluralismo jurídico democrático.

Hablo de pluralismo jurídico democrático porque creo necesario comenzar delimitando el campo, de la manera que se puede delimitar un campo, excluyendo. Y esto porque la Constitución ecuatoriana del 2008 otorgó reconocimiento a la justicia indígena, haciendo parte del esquema institucional de la participación y la organización del poder que fija el ámbito de acción habilitante de la Función Judicial.

Esto significa que el constitucionalismo ecuatoriano zanjó, en el nivel normativo y político más alto, la intensa, amplia y confusa discusión de la que se ha dado cuenta, muy brevemente, en el presente artículo sobre el Derecho, el Estado, la justicia institucional y el pluralismo jurídico. Hablo entonces de un pluralismo jurídico democrático porque asume de manera objetiva, dentro de las fronteras nacionales, la existencia de 'otro derecho' distinto al derecho estatal; y legitima 'otras prácticas de justicia' que, siendo distintas por su naturaleza y procedimientos, son obligatorias para los miembros que hacen parte de las comunidades y pueblos indígenas. En esta nueva convivencia, las decisiones de las autoridades indígenas gozan de la garantía del Estado para su eficacia. Y también es democrático porque resuelve por los cauces institucionales 
Del constitucionalismo clásico al constitucionalismo plural: la disputa por la capacidad regulatoria de la sociedad en perspectiva teórica

democráticos de más alto rango de legitimidad, el poder constituyente, lo que es el pluralismo jurídico.

En consecuencia, quedan excluidos de la formulación normativa constitucional el resto de manifestaciones que son englobadas en el pluralismo jurídico y que denotan dinámicas sociales de carácter normativo de las sociedades contemporáneas en el mundo de la vida.

El reconocimiento del derecho propio de los pueblos y nacionalidades indígenas del Ecuador y de la Justicia Indígena representa una forma de mediación entre lo universal y lo particular. Propone pensar al individuo en los límites del pluralismo democrático; añadir al escenario las colectividades y las identidades intersubjetivas diferenciadas; incluye las diferencias ontologizadas por efectos de las colonizaciones clásica y moderna y las inequidades y desigualdades; poner en escena 'otras' conflictividades para enfrentarlas y resolver los conflictos sin continuar ocultándolos o manteniéndolos latentes; mirar de frente a las diferencias y se deja influenciar e influencia al 'otro'.

Aquí no existen más ideales humanos comunes, los individualismos, colectivismos, humanismos, universalismos se relativizan; no reina la tolerancia sino la posibilidad de transformación intersubjetiva a través del diálogo intercultural.

Ni derecho individual, ni derecho privado; ni derecho burgués, ni derecho social; ni derecho de gentes, ni derecho internacional. El derecho de las sociedades complejas nos hace ver que el nuevo constitucionalismo debe ser un derecho de la sociedad: cosmopolita, con un grado de generalidad relativo; que arbitre el pluralismo moral existente sobre la base de parámetros republicanos, democráticos, comunitarios, participativos y deliberativos; que opera sobre la lógica cambiante, inestable e incierta del ritmo de las sociedades; que establece parámetros que regulan las actuaciones de las distintas manifestaciones sociales a distintos niveles: estructurales (organización del poder), institucionales, operativos, dinámicos, relacionales, confrontacionales; un derecho de la sociedad, no del Estado.

El reconocimiento de la Justicia Indígena en el Ecuador, hace posible la tesis de que por medio de diálogos transculturales se determinan las normas que regulan las relaciones interculturales. Hace posible también conectar las versiones del Derecho a la vida social y hacer del respeto a la diversidad social desde el Derecho y el reconocimiento de lo plural una característica de las democracias contemporáneas. 
Nada está resuelto aún, solo hay unas normas constitucionales que lo dicen, y hay una sociedad que desde la incertidumbre, de la inquietud de la paz a punto de estallar, de las historias nunca acabadas, busca hacerlas posibles. Los pocos pasos que se han dado hasta el momento, serán el material para continuar con el análisis aquí planteado.

A manera de corolario diré que aunque Latinoamérica es vista de manera general como un lugar de recepción de las teorías europeas y anglosajonas ${ }^{15}$, por lo que pocos autores latinoamericanos han entrado en el círculo de referencias y diálogos teóricos dentro del debate del constitucionalismo contemporáneo, sus transformaciones van cada vez adquiriendo mayor relevancia en el análisis teórico.

El debate en Latinoamérica ha sido profuso e intenso, aunque desordenado como también ocurre en otros contextos teóricos-, pero claramente asentado en una gama amplia de lecturas que van del pensamiento crítico y el pensamiento interdisciplinario, pasando por el pensamiento neocolonial, neomarxista, pluralista, ecologista, feminista, e incluyendo a la Teología de la Liberación. Este bagaje teórico disímil y complejo, que estimuló la discusión sobre los límites del Derecho centrado en la ley, alcanzó a diseñar un constitucionalismo democrático que apuesta por el rescate de lo público, por el fortalecimiento de la noción de soberanía popular, por la construcción constante de legitimidad basada en la participación ciudadana y que tiene la capacidad de responder a las necesidades de la sociedad cambiante y plural.

Por último, cabe insistir en señalar que el debate jurídico en América Latina está fuertemente vinculado a las demandas de transformación económicas, política y sociales, tarea aún pendiente, y en la que, por lo acontecimiento que vienen ocurriendo en varios países latinoamericanos desde inicios del nuevo siglo, me atrevo a sostener que se han dado un paso adelante y tres atrás.

\section{BIBLIOGRAFÍA}

ANDRADE, GRIJALVA y STORINI. La nueva constitución del Ecuador: Estado, derechos e instituciones. Quito: Corporación Editora Nacional, 2009.

BALlÓN. Manual del Derecho de los Pueblos Indígenas. Doctrina, principios y normas. Lima: Defensoría del Pueblo, 2004.

BORJA. Introducción a los fundamentos del derecho penal indígena. Valencia: Tirant lo Blanch, 2000. 
Del constitucionalismo clásico al constitucionalismo plural: la disputa por la capacidad regulatoria de la sociedad en perspectiva teórica

CHÁVEZ \& GARCÍA. El derecho a ser: diversidad, identidad y cambio. Etnografía jurídica indígena y afroecuatoriana. Quito: FLACSO Sede Ecuador - Petroecuador, 2004.

DE CABO, A. "Introducción” En: Aproximaciones al nuevo constitucionalismo.

Debate sobre sus fundamentos. Quito: Corte Constitucional, 2012.

ECUADOR. Constitución Política del Ecuador del 2008. Disponível em: <http://cancilleria.gob.ec/wp-content/uploads/2013/06/constitucion_2008.pdf>. Consultado en 29 de noviembre de 2017.

GARCÍA. Formas indígenas de administrar justicia. Estudio de caso de la nacionalidad quichua ecuatoriana. Quito, Ecuador: FLACSO, Sede Ecuador, 2002.

GARGARELLA. "Introducción” En:. Desafíos constitucionales, la Constitución ecuatoriana del 2008 en perspectiva. Quito: Ministerio de Derechos Humanos y Tribunal Constitucional, 2009.

HABERMAS. Debate sobre el liberalismo político. Barcelona: Paidós, 1998.

HART. Mandatos y razones jurídicas dotadas de autoridad. Ciudad del Mexico: Isonomía no . 6, 1997.

LLÁSAG. "Justicia indígena, ¿delito o construcción de la plurinacionalidad?" En: SANTOS, B.D.; GRIJALVA, A. (Edits.), Justicia indígena, plurinacionalidad e interculturalidad en Ecuador. Quito: Fundación Rosa Luxemburgo/Abya Yala, 2012.

LÓPEZ MEDINA. Teoría impura del derecho. La transformación de la cultura jurídica latinoamericana. Bogotá: Legis Editores, 2004.

MARTÍNEZ DALMAU y VICIANO PASTOR. Cambio político y proceso constituyente en Venezuela (1998-200). Valencia: Tirant lo blanch, 2011.

MILLER, WALZER, ELSER, MOLLER OKIN. Pluralismo, Justicia e Igualdad. Buenos Aires: Fondo de Cultura Económica de Argentina,1997.

MOUFFE. El retorno de lo político. Comunidad, ciudadanía, pluralismo, democracia radical. Barcelona: Paidós, 1999.

PAULSON. La interpretación débil de la autoridad en la Teoría Pura del Derecho de Hans Kelsen. Revista Derecho del Estado (29), 5-49, 2012.

PAZMIÑO. Aproximaciones al nuevo constitucionalismo. Debate sobre sus fundamentos. Ministerio de Derechos Humanos y Tribunal Constitucional. Quito, 2012.

RAWLS. Liberalismo político. Trad. Sergio René Madero Báez. México: Fondo de Cultura Económica, 1995.

SÁNCHEZ. Justicia y Pueblos Indígenas en Colombia. Bogotá: Universidad Nacional de Colombia, 2004. 
SANDEL. EI liberalismo y los límites de la justicia. Gedisa, 2000.

SANTOS. De la mano de Alicia: lo social y lo político en la postmodernidad. Bogotá: Ediciones Uniandes, 1998.

Refundación del Estado en América Latina. Perspectivas desde una epistemología del Sur. Quito, Ecuador: AbyaYala, 2010.

TAYLOR. El Multiculturalismo y la Política de Reconocimiento. México D.F.: Fondo de Cultura Económica, 1993.

TIBÁN, L.; ILAQUICHE, R. Manual de Administración de justicia indígena en el Ecuador. Latacunga: FUDEKI, 2004.

VICIANO PASTOR y MARTÍNEZ DALMAU. "Fundamentos teóricos y prácticos del nuevo constitucionalismo latinoamericano", Gaceta Constitucional, núm. 48 (diciembre), 2011.

WOLKMER. Pluralismo Jurídico. Fundamentos de una nueva cultura del Derecho. Colección universitaria Textos Jurídicos. España: MAD, 2006.

Artigo recebido em 13 de setembro de 2017 e aceito em 27 de dezembro de 2017

\footnotetext{
${ }^{1}$ Históricamente asentado en el legicentrismo o derecho centrado en la ley.

${ }^{2}$ Concibiendo un modelo de Estado finalista y cuyo papel consiste en cumplir los mandatos del poder constituyente.

${ }^{3}$ Esto lo hace: 1) poniendo a los derechos en el centro del Derecho; 2) asumiendo la igualdad de jerarquía de todos los derechos; 3) consolidando el catálogo de derechos humanos; 4) incorporando una cláusula abierta que permita incorporar todos los derechos que no se encuentren amparados en la constitución pero que sean atinentes a la dignidad humana. Con esto, no solo se reformulan las tesis gradualistas de los derechos, sino la propia tesis de los derechos fundamentales al borrar las distinciones entre tipos de derechos y las opciones ideológicas que representa la tesis de la jerarquía de derechos.
}

${ }^{4}$ Asumiendo, no solo un papel interventor del Estado en la economía para corregir las inequidades y desigualdades crónicas y persistentes, sino también declarando al sistema económico social y solidario que reconoce al ser humano como sujeto y fin; propende a una relación dinámica y equilibrada entre sociedad, Estado y mercado, en armonía con la naturaleza; y tiene por objetivo garantizar la producción y reproducción de las condiciones materiales e inmateriales que 
Del constitucionalismo clásico al constitucionalismo plural: la disputa por la capacidad regulatoria de la sociedad en perspectiva teórica

posibiliten el buen vivir. Dicho sistema está integrado por formas de organización económica pública, privada, mixta, popular y solidaria (Art. 283 de la C.R.E.).

${ }^{5}$ Reformulada sobre una concepción participativa del ejercicio y la organización del poder que reconoce una amplia variedad de formas de participación a las que dota de mecanismos, procedimientos y garantías para hacerlos efectivos.

${ }^{6}$ Para MARTÍNEZ DALMAU y VICIANO PASTOR (2011), el Nuevo Constitucionalismo Latinoamericano es un fenómeno surgido en el extrarradio de la academia, producto más de las reivindicaciones populares y de los movimientos sociales que de planteamientos teóricos coherentemente armados, aunque los procesos son disímiles existen unos rasgos comunes bastante definidos que permiten afirmar que se trata de una corriente constitucional en período de construcción doctrinal.

${ }^{7}$ Y como sostiene DE CABO, "se pone fin a una forma de entender el derecho constitucional como referencia a modelos pretéritos fuertemente idealizados y ajenos a la realidad local, y porque - paralelamente, se desbordan los marcos interpretativos creados en esos mismos países centrales (...) Así, a la emancipación nacional que recogen como proyecto y como realidad en estos textos constitucionales, le corresponde una emancipación del conocimiento y de la reflexión".

${ }^{8}$ Para esta discusión ver, fundamentalmente, SANTOS (2010).

${ }^{9}$ Los planteamientos centrales del presente artículo hacen parte de la tesis doctoral "El control constitucional de la justicia indígena en el Estado plurinacional e intercultural: el caso ecuatoriano" leída y aprobada en mayo de 2016 en la Universidad de Valencia, España. Como ponencia, fue presentado en el I Congreso Internacional de Justicia constitucional, democracia y relaciones sociales y I Muestra de trabajos científicos, realizado los días del 23 al 25 de agosto de 2017 en la ciudad de Passo Fundo, Brasil.

${ }^{10}$ Para una revisión de lo que representa el Nuevo Constitucionalismo Latinoamericano ver VICIANO PASTOR, 2012. También ver Corte Constitucional del Ecuador para el período de Transición, 2010; PAZMIÑO FREIRE, Aproximaciones al nuevo constitucionalismo. Debate sobre sus fundamentos, 2012; Ministerio de Derechos Humanos y Tribunal Constitucional, 2008; ANDRADE, GRIJALVA Y STORINI, 2009; VICIANO PASTOR Y MARTÍNEZ DALMAU, Cambio político y proceso constituyente en Venezuela (1998-2000), 2001; GARGARELLA (2009).

${ }^{11}$ Para SANTOS es interesante ver hasta qué punto los Derechos Humanos se han convertido en el lenguaje de la política progresista, cuando hasta después de la Segunda Guerra Mundial los Derechos Humanos eran en buena medida parte integral de la política de la Guerra Fría, frente a lo cual las fuerzas progresistas preferían el lenguaje de la revolución y el socialismo a la hora de formular una política emancipatoria (SANTOS, De la mano de Alicia: lo social y lo político en la postmodernidad, 1998, p. 245). En aquella época, SANTOS ya advertía que aquellas mismas fuerzas progresistas están volviéndose hacia los Derechos Humanos para reconstruir el lenguaje emancipatorio, lo que ha venido ocurriendo de manera intensa en las últimas décadas en América Latina y Europa.

12 Para un análisis de la autoridad como habilitación, ver el esclarecedor trabajo de PAULSON (2012), sobre La interpretación débil de la autoridad en la Teoría Pura del Derecho de KELSEN.

${ }^{13}$ Varios autores dan cuenta de que los procesos de juzgamiento dentro de las comunidades indígenas sigue un patrón propio, pero que, en términos generales, cubre las principales etapas procesales exigidas en un proceso judicial, a saber: denuncia, aboco de conocimiento, apertura de etapa de prueba, valoración de la prueba, análisis jurídico del caso, decisión (que incluye una sanción que puede ser incriminatoria o exculpatoria) (BALLÓN, 2004; BORJA, 2000; CHÁVEZ 
\& GARCÍA, 2004; GARCÍA, 2002; LLÁSAG, 2012; SÁNCHEZ, 2004; TIBÁN, ILAQUICHE 2004). Estas 'etapas procesales', no nos engañemos, ni transcurren con las formalidades y los tiempos de la justicia nacional, ni tienen los mismos significados ni objetivos de regulación del orden, por lo que el juez examinador dejará claro que se trata de un debido proceso 'propio' de las comunidades, pueblos y nacionalidades.

${ }^{14}$ No en vano LÓPEZ MEDINA (2004, p. 28) habla de que las lecturas de las teorías jurídicas dominantes que se hacen en los centros periféricos del conocimiento -en donde hay una tradición justeórica 'débil'- están plagadas de malas copias, tergiversaciones, adaptaciones y transformaciones que no solo explican las dinámicas, sino que además permiten que se produzcan interesantes adaptaciones y verdaderas creaciones en los lugares de recepción.

${ }^{15}$ Uno de los trabajos más importantes para comprender las razones de los imaginarios que giran alrededor del desconocimiento teórico del pensamiento Latinoamericano lo encontramos en el trabajo de LÓPEZ (2004). 